\title{
Kontrol Kunci Pintu Rumah Menggunakan Raspberry Pi Berbasis Android
}

\author{
Gede Widya Dharma, I Nyoman Piarsa, I Made Agus Dwi Suarjaya \\ Program Studi Teknologi Informasi Universitas Udayana \\ Bukit Jimbaran, Bali, Indonesia, telp. (0361) 701806 \\ e-mail: gede.widya.dharma@gmail.com, manpits@unud.ac.id, agussuarjaya@it.unud.ac.id
}

\begin{abstract}
Abstrak
Tingkat kejahatan kasus pembobolan rumah terus meningkat, berdasarkan data yang dikumpulkan oleh Badan Pusat Statistik kasus pembobolan rumah menempati posisi kedua dengan jumlah kasus terbanyak. Perkembangan teknologi memberikan solusi dalam sebuah sistem keamanan yang lebih baik. Berbagai sistem otomatisasi telah dikembangkan, salah satunya tentang penguncian pintu, yang harus memiliki sebuah sistem keamanan yang dapat diandalkan. Penelitian yang dilakukan bertujuan untuk mengembangkan sebuah prototype kontrol kunci pintu menggunakan Raspberry Pi berbasis android yang dilengkapi dengan magnetic switch door, solenoid dan alarm. Sistem dilengkapi dengan fitur alarm dan kunci otomatis yang dapat diaktifkan melalui aplikasi android. Fitur alarm akan aktif ketika pintu terbuka pada mode terkunci, sedangkan fitur kunci otomatis akan aktif ketika pintu sudah tertutup beberapa menit. Status pintu sudah terkunci atau belum dapat dilihat pada aplikasi android, serta melakukan penguncian pintu dari jarak jauh. Hasil dari prototype yang dikembangkan yaitu dapat meningkatkan keamanan pada pintu rumah dari tindak kejahatan pembobolan pintu.
\end{abstract}

Kata kunci: Android, Keamanan, Pintu, Raspberry Pi

\begin{abstract}
The crime rate of home burglary cases increases every year, based on data collected by tribunnews.com cases of house burglary occupy the second place with the highest number of cases. Technological developments provide solutions in a better for security system. Various automation systems have been developed, one of which is about locking doors. The door must have a reliable security system. In this study developed a door lock control using Raspberry Pi equipped with magnetic door switches, solenoids and alarms. Trial this system is equipped with an alarm feature and an automatic lock that can be activated via the Android application. The alarm feature will activate when the door opens in locked mode, while the lock feature will automatically activate when the door is closed a few minutes. Through the application can also see if the door is locked or not, and do the locking of the door remotely. It is hoped that later this system can improve security at the door of the house from a door breaking crime.
\end{abstract}

Keywords : Android, Door, Raspberry Pi, Security

\section{Pendahuluan}

Tingkat kejahatan kasus pembobolan rumah meningkat setiap tahunnya, berdasarkan data yang dikumpulkan oleh Badan Pusat Statistik menyatakan jumlah kejadian pada tahun 2014 sebanyak 11.758 kasus, menjadi sebanyak 11.856 kasus pada tahun 2015, dan meningkat pada 2016 menjadi 12.095 kasus [1]. Kasus-kasus pembobolan rumah biasanya terjadi jika keadaan rumah kosong dan tanpa pengawasan. Sistem keamanan yang kurang baik, akan mempermudah pelaku tindak kejahatan untuk melakukan pembobolan rumah.

Perkembangan teknologi digital dan elektronika dapat memberikan sebuah solusi dalam sistem keamanan rumah yang lebih baik. Banyak sistem otomatisasi yang telah dikembangkan, salah satunya tentang penguncian pintu. Pintu merupakan bagian yang sangat penting dalam rumah, sebab pintu memiliki peran sebagai akses terhadap tempat atau barang didalam rumah yang bersifat privas. Pintu harus memiliki sebuah sistem keamanan yang dapat diandalkan. Secara umum pintu yang dibuka dan ditutup secara manual, dapat untuk 
diotomatisasi sehingga dapat mempermudah berbagai kegiatan-kegiatan manusia dan juga dilengkapi dengan sistem keamanan yang terintegrasi.

Penelitian terkait sistem keamanan pintu sudah pernah dilakukan oleh Lwin, Khaing dan Tun yang berjudul "Automatic Door Access System Using Face Recognition", memaparkan tentang sistem keamanan pada pintu menggunakan pengenalan citra wajah. Wajah dideteksi dengan menggunakan metode Viola Jones dan pengenalan wajah diimplementasikan dengan menggunakan Principal Component Analysis (PCA). Pintu akan terbuka secara otomatis jika citra wajah dikenali, di sisi lain, alarm akan berbunyi untuk citra wajah yang tidak dikenal [2]. Penelitian yang dilakukan oleh Septryanti dan Fitriyanti yang berjudul "Rancang Bangun Aplikasi Kunci Pintu Otomatis Berbasis Mikrokontroler Arduino Menggunakan Smartphone Android", memaparkan tentang rancangan sistem kunci pintu menggunakan perangkat android melalui media Bluetooth dan QRCode. Media Bluetooth digunakan untuk mengkunci pintu dan QRCode digunakan untuk membuka kunci pintu. Proses kunci pintu tidak akan berfungsi jika perangkat android berada diluar dari pancaran wireless Bluetooth module karena sambungan Bluetooth akan secara otomatis terputus. Kunci pintu akan terbuka dengan melakukan scan QRCode yang teridentifikasi antara aplikasi dan mikrokontroler [3]-[4]. Penelitian yang berjudul "Sistem Pengamanan Pintu Rumah Otomatis via SMS Berbasis Mikrokontroller ATMega328P" yang dilakukan oleh Asad, Nurhayati dan Widianto, telah merancang keamanan pintu otomatis menggunakan SMS, yang berfungsi sebagai pengaman untuk pintu berbasis mikrokontroler. Telepon dengan fasilitas SMS digunakan sebagai media yang terdiri dari sensor sebagai input dari pintu ke mikrokontroler. Penelitian ini menggunakan mikrokontroller ATmega328P. Wavecom GSM Modem M1306B digunakan sebagai pengirim dan penerima SMS, menggunakan solenoid untuk mengunci pintu, dan menggunakan bel untuk alarm [5].

Penelitian yang dilakukan yaitu merancang prototype sistem kontrol kunci pintu menggunakan raspberry pi berbasis android dilengkapi dengan magnetic switch door untuk mendeteksi pintu sedang terbuka atau tertutup, dan solenoid sebagi kunci dalam sebuah pintu. Hasil dari prototype sistem kunci pintu yaitu dapat membuka atau mengkunci pintu melalui aplikasi pada perangkat android. Fitur alarm dan kunci pintu otomatis yang dapat diaktifkan melalui aplikasi untuk meningkatkan keamanan pintu rumah dari tindak kejahatan pembobolan pintu. Fitur alarm akan aktif ketika pintu terbuka pada mode terkunci, sedangkan fitur kunci otomatis akan aktif ketika pintu tertutup selama beberapa menit. Fokus penilitian yang dilakukan yaitu merancang sebuah sisem kontrol kunci pintu menggunakan mikrokontroller raspberry pi yang dapat digunakan dari jarak jauh memalui jaringan internet. Pengembangan teknologi identifikasi telah diterapkan pada macam-macam perangkat salah satunya pada smartphone berbasis Android [6], sehingga aplikasi kontrol kunci pintu dibuat pada smartphone dengan platform Android.

\section{Metodologi Penelitian}

Metodologi penelitian yang digunakan adalah SDLC (Software Development Life Cycle) model waterfall. Model Waterfall merupakan model yang paling sering digunakan dalam penelitinan dibandangkan dengan model yang lain dalam SDLC. Model waterfall adalah model pengembangan yang prosesnya berjalan secara linier dan berurutan serta merupakan model yang pertama terbentuk. Setiap tahap harus diselesaikan sebelum melanjutkan ke tahap berikutnya. 


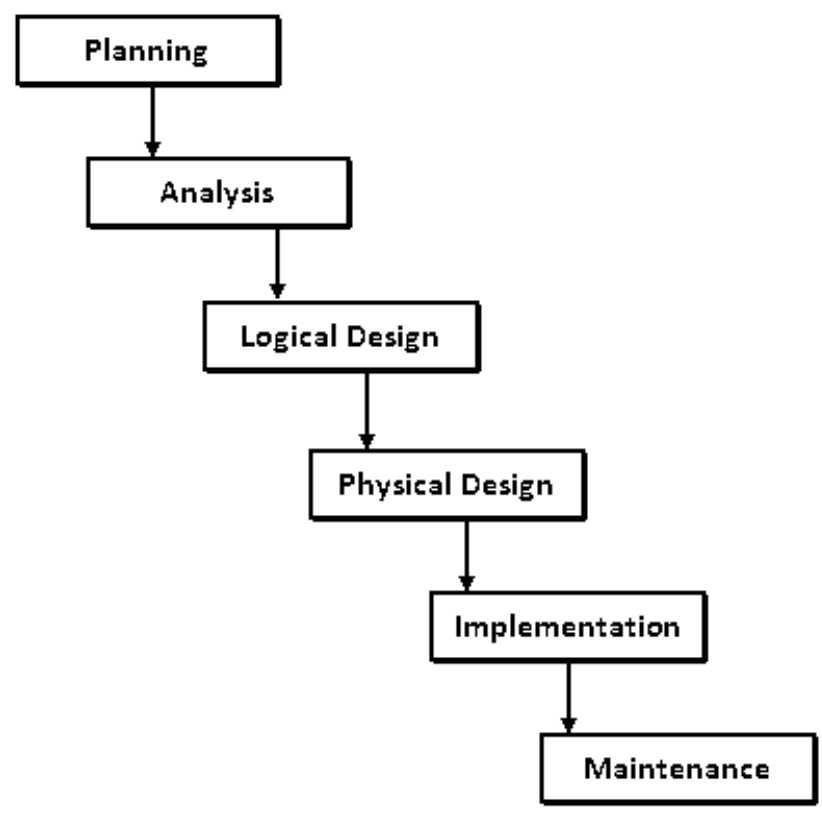

Gambar 1. Metodologi Penelitian SDLC model Waterfall

Tahapan model waterfall yang digunakan dalam penelitian sistem kontrol kunci pintu rumah dapat dilihat pada Gambar 1. Terdapat 7 tahap yaitu Planning, Analysis, Logical Design, Pysical Design, Implementation, Maintenance. Tahap Planning merupakan tahapan perencanaan dalam pembuatan prototype sistem kontrol kunci pintu. Tahap analysis mengumpulkan kebutuhan secara lengkap kemudian dianalisis dan didefinisikan kebutuhan yang harus dipenuhi oleh sistem yang akan dibangun. Tahap Logical Design merancang flowchart alur kerja sistem agar setiap proses dapat berjalan sesuai rencana. Tahap physical design merancang rangkaian sensor dengan raspberry pi agar dapat terintegrasi antara sensor dan mikrokontroller. Tahap implementation merupakan tahapan mengimplementasikan logical design dan physical design ke sistem. Tahap maintenance merupakan tahap untuk melakukan perbaikan apabila sistem yang telah dirancang belum sesuai rencana.

\subsection{Gambaran Umum Sistem}

Membahas keseluruhan rancangan kerja dan sistem sistem kontrol kunci pintu rumah menggunakan mikrokontroler raspberry pi berbasis android.
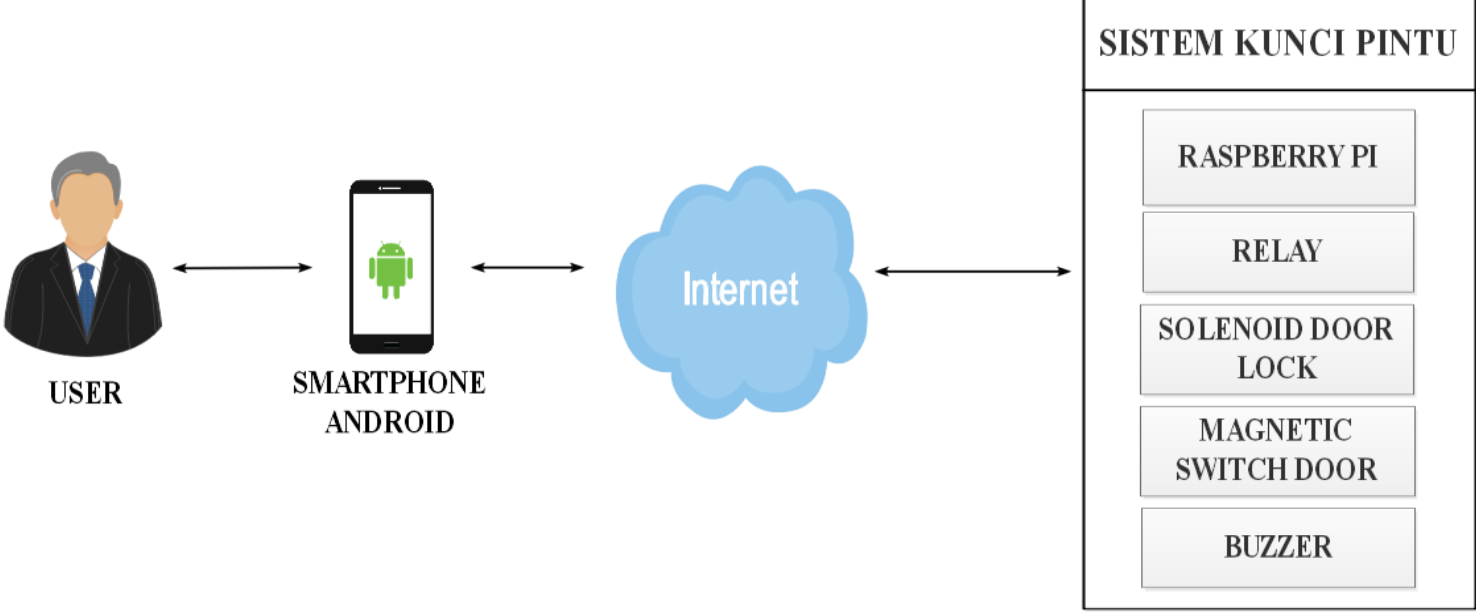

Gambar 2. Gambaran Umum Sistem 
Gambar 2 merupakan gambaran umum sistem kontrol kunci pintu rumah menggunakan mikrokontroller raspberry pi berbasis android. Mikrokontroller raspberry pi sebagai pusat kontrol pada sensor yang terhubung yaitu magnetic switch door, relay, solenoid door lock dan buzzer. Raspberry $\mathrm{Pi}$ akan mengolah data yang diterima dari sensor dan mengirimkannya ke server melalui internet dan layanan webservice untuk menyimpan data ke database. Melalui aplikasi pada perangkat android, user dapat melakukan manajemen kontrol terhadap mikrokontroller raspberry pi yang terhubung ke jaringan internet.

\section{Kajian Pustaka}

Semua pustaka yang dijadikan acuan pada penelitian baik yang bersumber dari buku, internet ataupun jurnal lain akan diuraikan sebagai berikut.

\subsection{Raspberry Pi}

Raspberry Pi merupakan mini komputer single-board yang memiliki fitur hampir sama dengan komputer pada umumnya, seperti menjalankan program, office, menonton video resolusi tinggi, dan lain sebagainya yang dibuat oleh Raspberry Pi Foundation [7]. Raspberry pi cukup popular dibandingkan beberapa SBC yang lain seperti BeagleBone, Intel Galileo, PandaBoard dan lain-lain. Raspberry Pi awalnya dibuat untuk proses pembelajaran komputer bagi siswa-siswa sekolah, dan sekarang dapat digunakan untuk berbagai aplikasi seperti home automation, web server, file server [8].

Komponen yang ada pada Raspberry Pi yaitu ARM CPU/GPU adalah sistem Broadcom BCM2835 pada Chip (SoC) yang terdiri dari ARM Central Processing Unit (CPU) dan Video Core 4 Graphics Processing Unit. CPU menangani semua perhitungan yang membuat komputer bekerja (mengambil input, melakukan perhitungan dan menghasilkan output), dan GPU menangani keluaran grafis. GPIO memiliki tujuan utama sebagai koneksi input dan output umum yang digunakan untuk menerima input atau mengirimkan output ke sensor. RCA merupakan sebuah RCA jack yang memungkinkan koneksi dari televisi analog dan perangkat output lain. Audio out adalah jack standar 3,55 milimeter untuk koneksi dari perangkat output audio seperti headphone atau speaker. USB merupakan port koneksi umum untuk perangkat periferal dari semua jenis. HDMI merupakan konektor yang digunakan untuk menghubungkan televisi definisi tinggi atau perangkat lain yang kompatibel menggunakan kabel HDMI. Power adalah konektor power Micro USB 5V untuk dipasang power supply yang kompatibel. Kartu memori adalah kartu yang berfungsi sebagai media penyimpanan pada Raspberry Pi. Kartu memori berisi sistem operasi yang digunakan untuk menjalankan Raspberry Pi [9].

\subsection{Relay}

Relay merupakan komponen elektronika seperti saklar yang dioperasikan dengan arus listrik. Relay digunakan sebagai kontrol motor AC dengan rangkaian kontrol DC dengan sumber tegangan berbeda antara tegangan rangkaian kontrol dengan tegangan beban. Relay dibutuhkan dalam rangkaian elektronika sebagai eksekutor sekaligus interface antara beban dan sistem kendali elektronik yang berbeda sistem power supply [10].

\subsection{Solenoid Door Lock}

Solenoid door lock merupakan perangkat elektronik kunci pintu dengan menggunakan tegangan listrik sebagai pengendalinya [11]. Solenoid pengunci pintu bekerja jika diberi tegangan. Solenoid mempunyai dua proses kerja, yaitu normaly close (NC) dan normaly open (NO). Solenoid akan aktif atau bekerja apabila adanya tegangan. Tegangan Solenoid Door Lock adalah 12 volt. Secara normal solenoid berada dalam posisi tuas memanjang atau terkunci, jika diberi tegangan sebesar $12 \mathrm{~V}$ tuas akan memendek atau terbuka. Salah satu pin pada Solenoid akan dihubungkan dengan sumber listrik dengan tegangan 12 volt, dan pin yang lainnya akan dihubungkan ke Relay. Relay akan mengontrol kondisi Solenoid dengan cara memutuskan atau mengubungkan arus listrik.

\subsection{Magnetic Switch Door}

Magnetic Switch Door merupakan saklar yang dapat merespon medan magnet yang berada disekitarnya, biasanya digunakan sebagai modul pendeteksi bukaan/tutupan pintu atau aplikasi lainnya yang bekerja berdasarkan prinsip elektromagnetik [11]. Magnetic switch door 
bekerja berdasarkan ada tidaknya medan magnet yang mempengaruhi saklar. Secara umum keadaan sensor adalah normaly open (NO). Ketika magnet berasda didekat sensor maka dua posisi switch akan tersambung sehingga keadaanya adalah normally closed (NC). Ketika magnet dijauhkan, maka posisi switch akan kembali ke posisi normally open (NO). Magnetic Switch Door memiliki 2 pin, yaitu GND yang dihubungkan pada pin ground di Raspbery Pi dan pin output yang akan dihubungkan pada pin GPIO Rapsberry Pi.

\subsection{Buzzer}

Buzzer merupakan sebuah komponen elektronika yang dapat mengubah getaran listrik menjadi getaran suara. Buzzer merupakan salah satu perangkat audio yang sering digunakan pada rangkaian anti maling, alarm dan perangkat peringatan bahaya lainnya [12].

\subsection{Android}

Android merupakan sistem operasi yang terdiri dari middleware serta aplikasi-aplikasi dasar yang sudah sangat umum digunakan. Basis sistem operasi Android adalah kernel linux 2.6 yang telah diperbarui untuk mobile device. Pengembangan aplikasi berbasis Android menggunakan bahasa pemrograman java, yang berhubungan dengan pemrograman berbasis objek (OOP). Pengembangan aplikasi berbasis Android membutuhkan Software Development Kit (SDK) yang disediakan langsung oleh Android, SDK berperan sebagai jalan bagi programmer untuk mengakses Application Programming Interface (API) pada Android [13].

\section{Hasil dan Pembahasan}

Memaparkan tentang hasil uji coba dari setiap fitur yang ada pada sistem kontrol kunci pintu rumah menggunakan mikrokontroller raspberry pi berbasis android.

\subsection{Prototype}

Rangkaian diimplementasikan pada sebuah maket yang berbentuk pintu dengan ukuran panjang $40 \mathrm{~cm}$ dan lebar $20 \mathrm{~cm}$. Bagian dalam maket tersebut berisi rangkaian sistem yang ditempatkan sedemikian rupa untuk merancang kunci pintu cerdas. Rangkaian tersebut berisi Raspberry $\mathrm{Pi}$ sebagai mikrokontroller yang terhubung dengan magnetic swtich door, relay, solenoid dan buzzer.

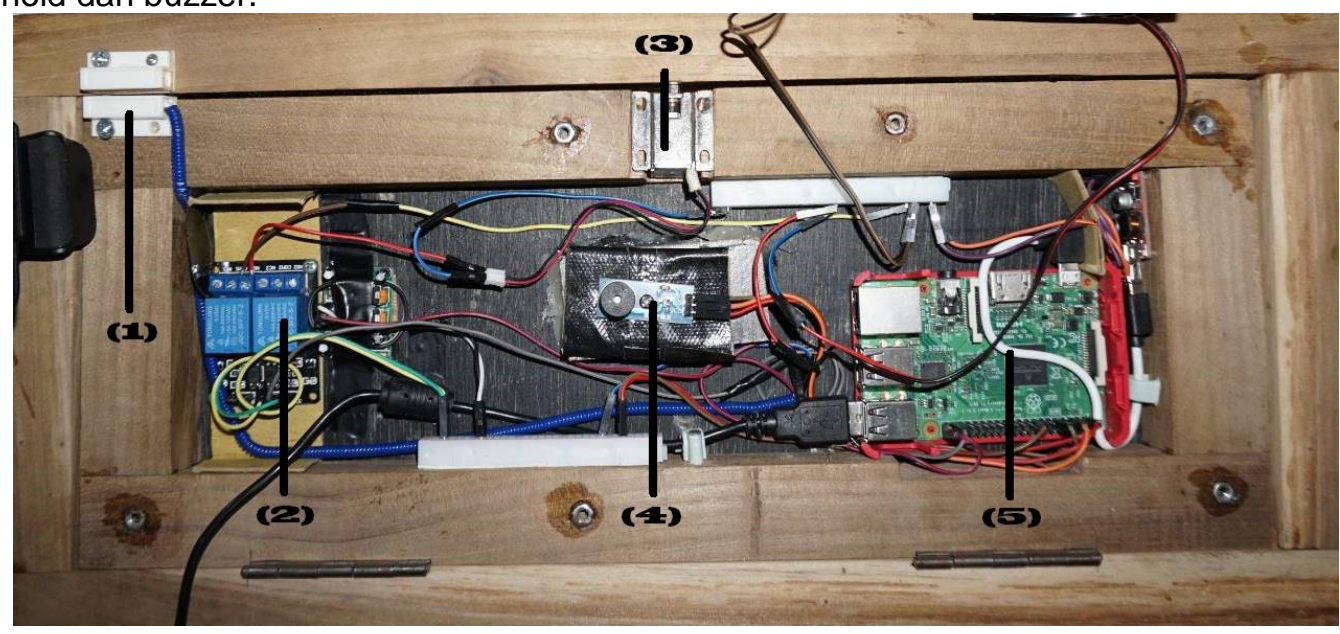

Gambar 3. Prototype Sistem

Rangkaian prototype sistem kontrol kunci pintu rumah menggunakan raspberry pi berbasis android dapat dilihat pada Gambar 3. Point (1) merupakan magnetic switch door untuk mendeteksi pintu sedang terbuka atau tertutuo, point (2) merupakan relay yang berfungsi untuk mengatur arus listrik solenoid, point (3) merupakan solenoid sebagai kunci pintu, point (4) merupakan buzzer sebagai alarm dan point (5) merupakan raspberry pi sebagai mikrokontroller untuk melakukan pengolahan data.

\subsection{Uji Coba Kontrol Kunci Pintu}


Uji coba kontrol kunci pintu dilakukan dengan memberikan perintah berupa membuka atau mengkunci pintu pada aplikasi android dan membandingkannya dengan rangkaian perangkat apakah sudah sesuai dengan perintah yang diberikan.

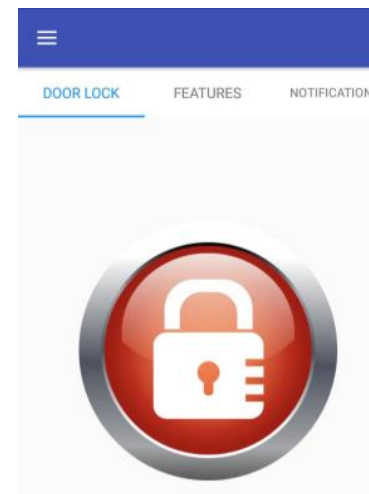

a.

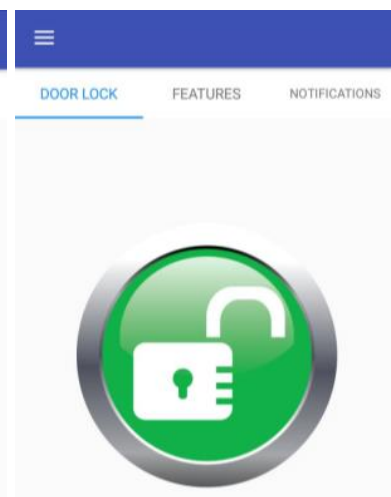

b.

Gambar 4. User Interface Kontrol Kunci pada Aplikasi Android a. Pintu Terkuci, b. Kunci Pintu Terbuka

Kontrol kunci memiliki 2 user interface untuk membedakan status dari kunci pintu, yaitu Gambar 4.a yang memiliki button berawarna merah dengan icon gembok terkunci menunjukan status pintu dalam keadaan terkunci sedangkan Gambar 4.b memiliki button berwarna hijau dengan icon gembok terbuka menunjukan status kunci pintu dalam keadaan terbuka. Tombol tersebut memiliki fungsi untuk merubah status kunci pintu pada database, ketika tombol berwarna merah ditekan sehingga menjadi tombol berwarna hijau, maka status pada database yang awalnya "terkunci" menjadi "terbuka".

Percobaan dilakukan yaitu membuka dan mengkunci pintu melalui aplikasi android. Kondisi awal pintu dalam keadaan terkunci, dapat dilihat pada tombol berwarna merah dengan icon gembok terkunci dan solenoid berada di luar.

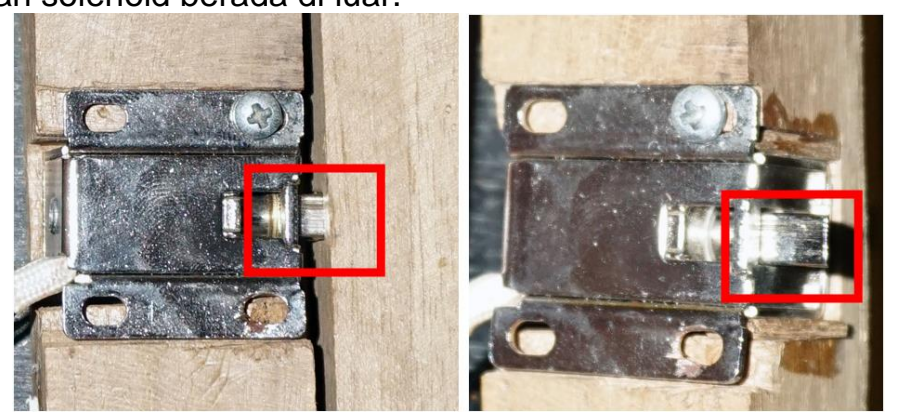

Gambar 5. Keadaan Solenoid Terkunci

Gambar 5 merupakan kondisi solenoid dalam keadaan terkunci. Kondisi pintu yang awalnya sedang terkunci, dapat dibuka melalui aplikasi android pada user interface kontrol kunci dengan menekan tombol yang semula berwarna merah dengan icon gembok terkunci (seperti Gambar 4.a). Jika berhasil membuka kunci pintu maka tombol akan menjadi berawarna hijau dengan icon gembok terbuka (seperti Gambar 4.b), dan solenoid akan masuk dan berada pada posisi didalam. 


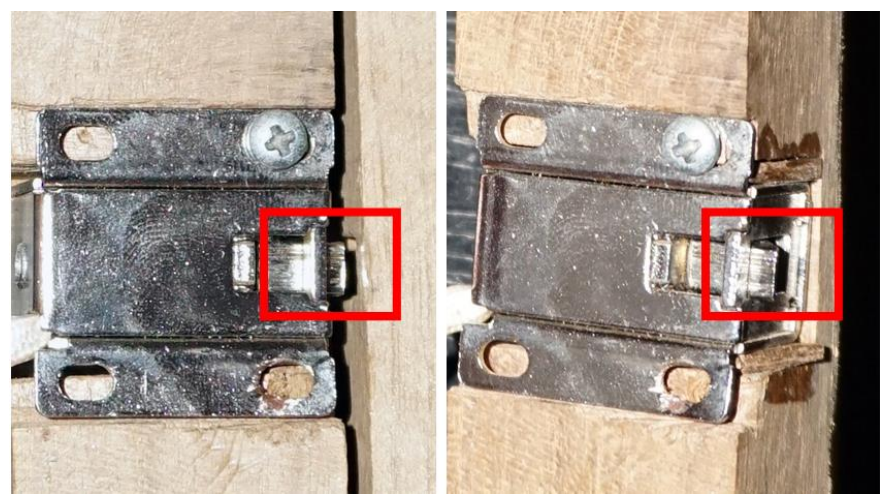

Gambar 6. Keadaan Solenoid Terbuka

Gambar 6 merupakan kondisi solenoid dalam keadaan terbuka. Percobaan kontrol kunci pintu melalui aplikasi android telah berhasil dilakukan. Pengguna dapat membuka atau mengkunci pintu dari jarak yang jauh melalui aplikasi pada smartphone android yang terhubung ke internet.

\subsection{Uji Coba Sistem Keamanan}

Uji coba sistem keamanan terdiri dari uji coba kunci otomatis dan alarm. Fitur kunci otomatis dan alarm harus diaktifkan terlebih dahulu melalui aplikasi android untuk dapat melakukan uji coba sistem keamanan pada sistem yang telah dibuat.

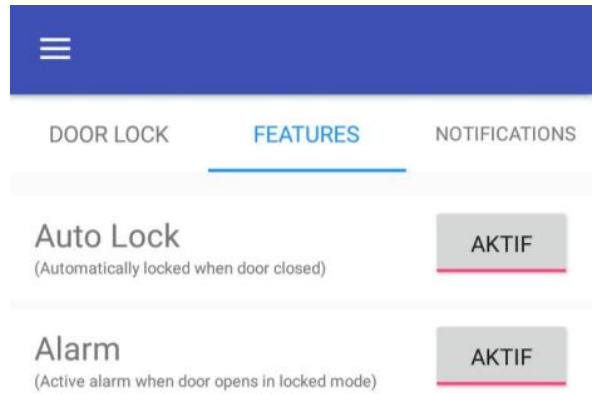

Gambar 7. Fitur Kunci Otomatis dan Alarm Aktif

Gambar 7 merupakan tampilan untuk mengaktifkan fitur kunci otomatis dan alarm pada aplikasi android. Percobaan kunci pintu otomatis dilakukan dengan memberikan durasi selama 10 detik, artinya jika pintu ditutup dalam keadaan tidak terkunci selamat 10 detik, raspberry pi akan mengubah status kunci pintu menjadi "terkunci" sehingga relay menjadi normally close (NC) dan ujung solenoid akan keluar.

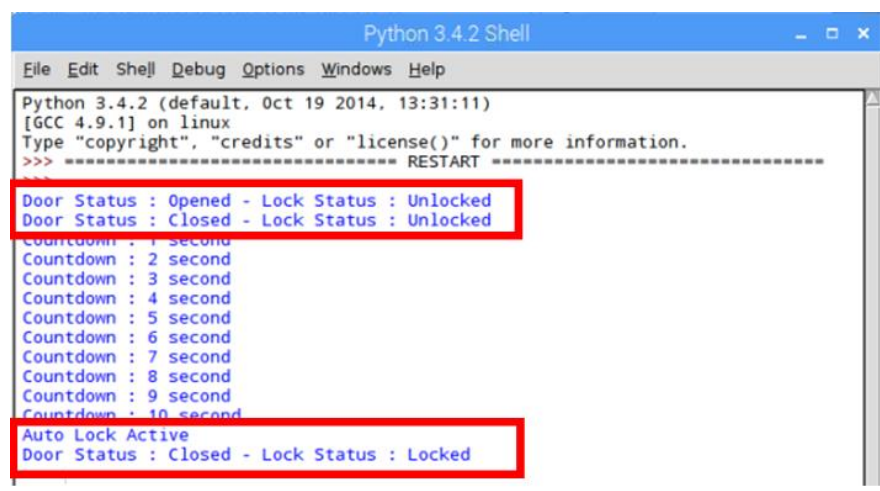

Gambar 8. Kunci Otomatis 
Gambar 8 merupakan tampilan pada saat kode program dijalankan untuk kunci otomatis diaktifkan. Pada baris pertama, sensor mendeteksi pintu dalam keadaan terbuka, dan status solenoid masih normally open (NO) sehingga status kunci 'Unlocked'. Pintu kemudian ditutup sehingga sensor mendeteksi pintu dalam keadaan tertutup dan solenoid masih dalam keadaan NO. Setelah pintu tertutup, waktu mulai terhitung, jika sampai 10 detik, status pintu masih tertutup, maka solenoid akan berubah menjadi NC dan status kunci menjadi "Locked".

Percobaan fitur alarm dilakukan dengan menutup pintu dengan keadaan terkunci, dan membuka pintu secara paksa dengan memberikan celah pada ujung solenoid (seolah-olah pintu sedang di bobol) sehingga pintu berhasil dibuka tanpa harus membuka kuncinya terlebih dahulu melalui aplikasi. Saat raspberry pi mendeteksi pintu terbuka secara paksa, dapat dilihat jika status dari magnetic switch door bernilai False (pintu terbuka karena kedua sisi magnetic switch door tidak berhadapan sejajar) sedangkan status 'kunci pintu' pada database masih 'terkunci', maka raspberry pi akan mengaktifkan alarm.

\section{Kesimpulan}

Prototype sistem kontrol kunci pintu rumah menggunakan raspberry pi berbasis android memberikan solusi untuk pemilik rumah dengan memberikan kemudahan dalam melakukan proses kontrol kunci pintu yang dapat dilakukan dari jarak yang jauh melalui jaringan internet dan aplikasi berbasis android sebagai Graphical User Interface (GUI). Aplikasi android digunakan untuk menerima intruksi perintah dari pengguna dan disampaikan ke mikrokontroller raspberry pi untuk mengontrol sensor seperti magnetic switch door untuk mendeteksi keadaan pintu sedang terbuka atau tertutup, solenoid dan relay sebagai kunci pintu dan buzzer yang digunakan sebagai alarm.

\section{Daftar Pustaka}

[1] Badan Pusat Statistik. (2017). Statistik Kriminal 2017. Jakarta: BPS.

[2] H. H. Lwin, A. S Khaing dan H. M. Tun, (2015) 'Automatic Door Access System Using Face Recognition', International Journal of Scientific \& Technology Research, 4(6), pp. 294-299.

[3] A. Septryanti dan Fitriyanti, (2017) 'Rancang Bangun Aplikasi Kunci Pintu Otomatis Berbasis Mikrokontroler Arduino Menggunakan Smartphone Android', Journal Of Computer Engineering System And Science, 2(2), pp. 59-63.

[4] M. R.Asad, O. D. Nurhayati and E. D. Widianto, (2015) 'Sistem Pengamanan Pintu Rumah Otomatis via SMS Berbasis Mikrokontroller ATMega328P', Jurnal Teknologi dan Sistem Komputer, 3(1), pp. 1-7.

[5] K. S. Wibawa and I N. Piarsa, (2018) 'Secure Data Monitoring System with Encrypt Data Transmission over Radio Communication Based on Microcontroller', International Journal of Computer Applications, 179(21), pp. 19-22.

[6] I K. S. Widiakumara, I. K. G. D. Putra and K. S. Wibawa, (2017) 'Aplikasi Identifikasi Wajah Berbasis Android', Lontar Komputer, 8(3), pp. 200-207.

[7] Adnyana, I N. Piarsa, and K. S. Wibawa, (2018) 'Internet of Things : Control and Monitoring System of Chicken Eggs Incubator Using Raspberry Pi', International Journal of Internet of Things, 7(1), pp. 16-21.

[8] R. Edir, C. Faisal dan D. S. Fajar, (2015) RaspberryPi: Mikrokontroler Mungil yang Serba Bisa, Yogyakarta: Andi Publisher.

[9] D. Kurniawan, (2016) Membangun Aplikasi Elektronika dengan Rapsberry Pi 2 dan WhatsApp. Jakarta: Elex Media Komputindo.

[10]A. O. T. Daniel, (2015) Pengembangan Sistem Relay Pengendalian Dan Penghematan Pemakaian Lampu Berbasis Mobile. Seminar Nasional Informatika 2015. Yogyakarta.

[11]A. Apriansyah, Ilhamsyah and T. Rismawan, (2016) 'Prototype Kunci Otomatis Pada Pintu Berdasarkan Suara Pengguna Menggunakan Metode KNN (K-Nearest Neighbor)', Jurnal Coding, Sistem Komputer Untan, 04(1), pp. 45-56.

[12] D. A. K. Arimbawa, I. K. G. D. Putra and I M. Sukarsa, (2018) 'Library System Using Radio Frequency Identification ( RFID ) and Telegram Bot API', Lontar Komputer, 9(1), pp. 40-51.

[13]A. D. Kasman, (2015) Trik Kolaborasi Android dengan PHP dan MySQL. Yogyakarta: CV. Lokomedia. 